\title{
ANTIBIOTIC PROPHYLAXIS IN TOTAL HIP ARTHROPLASTY
}

\author{
REVIEW OF 10905 PRIMARY CEMENTED TOTAL HIP REPLACEMENTS REPORTED TO \\ THE NORWEGIAN ARTHROPLASTY REGISTER, 1987 TO 1995
}

B. ESPEHAUG, L. B. ENGESAETER, S. E. VOLLSET, L. I. HAVELIN, N. LANGELAND

From the University of Bergen, Haukeland University Hospital and

Buskerud Central Hospital, Norway

We have assessed the effect of different regimes of antibiotic prophylaxis on the survival of total hip implants, comparing antibiotics administered both systemically and in the bone cement, systemically only, in the bone cement only and with no antibiotics given.

We studied 10905 primary cemented total hip replacements, performed for osteoarthritis of the hip and reported to the Norwegian arthroplasty register between 1987 and 1995. Cox-estimated failure-rate ratios (FRR) are presented with adjustment for gender, age, the brand of cement, the prosthesis, the type of operating theatre and the operating time.

For revisions performed for infection (39 operations), the lowest rate of revision was found among patients receiving antibiotic-containing cement plus systemic antibiotics $(n=5804)$. The revision rate for the 4586 patients receiving systemic antibiotics only was 4.3 times greater $(95 \%$ CI 1.7 to $11.0, p=0.001)$; in 239 with antibiotics in the bone cement only it was 6.3 times greater (CI 1.6 to 25.0, $\mathrm{p}=\mathbf{0 . 0 0 3}$ ); and in the 276 who did not receive antibiotics it was by 11.5 times greater (CI 2.1 to $63.0, p=0.002$ ). Adjustment for the total amount of systemic antibiotic administered did not change the results. We also observed an increased revision rate for aseptic loosening (109 operations) comparing the systemic-only $(F R R=1.8$, CI 1.1 to 2.9,

B. Espehaug, MSc, Research Fellow

S. E. Vollset, MD, DrPH, Professor

Division for Medical Statistics, Department of Public Health and Primary Health Care, University of Bergen, Armauer Hansens Building, N-5021, Bergen, Norway.

L. B. Engesaeter, MD, PhD, Professor, Chief Orthopaedic Surgeon

L. I. Havelin, MD, PhD, Chief Orthopaedic Surgeon

Department of Orthopaedics, Haukeland University Hospital, N-5021 Bergen, Norway.

N. Langeland, MD, PhD, Chief Orthopaedic Surgeon

Department of Orthopaedics, Buskerud Central Hospital, N-3004 Drammen, Norway.

Correspondence should be sent to Mrs B. Espehaug.

(c)1997 British Editorial Society of Bone and Joint Surgery 0301-620X/97/47420\$2.00 $\mathrm{p}=0.01)$ and the cement-only regimes $(\mathrm{FRR}=\mathbf{2 . 6}, \mathrm{CI}$ 1.2 to $5.9, p=0.02$ ) with the combined dosage.

Our findings show that systemic antibiotics combined with antibiotic-containing bone cement led to fewer revisions than the other methods.

J Bone Joint Surg [Br] 1997;79-B:590-5.

Received 18 November 1996; Accepted after revision 23 January 1997

There is a wide range of options available during total hip replacement (THR). ${ }^{1}$ Previous studies have shown that the use of low- and high-viscosity cement, of cemented or cementless prostheses, and the design of the prosthesis may all substantially influence the survival of the implant. ${ }^{2-8}$

The use of prophylactic systemic antibiotics is well established both in general surgery and joint replacement, ${ }^{9-12}$ but there are large variations in the dosage and duration of use and in the inclusion of antibiotics in the bone cement. One large, randomised trial compared the effect of antibiotics given either systemically or in the cement. No statistically significant difference was found, but the study suggested that combined use may be preferable to antibiotics administered either only in cement or only systemically. ${ }^{13}$ Further investigations of this issue have been called for. ${ }^{14}$

Our study compares the effect on implant survival of the different regimes of antibiotic prophylaxis used for hip arthroplasty in Norway, particularly with regard to the possible benefit of adding antibiotics to bone cement, using information from the Norwegian arthroplasty register which records all THRs carried out in the country since 1987.

\section{PATIENTS AND METHODS}

Since September 1987, information on almost all primary THRs and all revisions performed at 68 hospitals in Norway has been recorded in the Norwegian arthroplasty register. After each operation, a standard form is completed by the surgeon and sent to the register. An English translation of the form has been given in a previous report. ${ }^{15}$ Revisions, defined as a surgical removal or exchange of a part of or the whole implant, were linked to the data already 
collected on the primary operations by using the unique number assigned to each inhabitant of Norway.

For primary THRs performed from 1987 to 1995, we compared the time until revision for four groups as follows:

1) patients receiving antibiotic prophylaxis both systemically and locally in the bone cement (combined regime);

2) those receiving antibiotics systemically only (systemiconly regime);

3) those receiving antibiotics in the cement only (cementonly regime); and

4) those receiving no antibiotic prophylaxis (no antibiotic regime).

A total of 38835 primary operations had been performed during the study period. To investigate the effect of the use of antibiotics in a relatively homogeneous population, we included only patients operated on for primary osteoarthritis of the hip who had not had a previous operation $(\mathrm{n}=25$ 737). Cement had been used in both components in $86 \%$ of these operations. Previous reports based on information from the Norwegian arthroplasty register have shown that particular brands of cement and types of prosthesis have been rarely used or have given poor results. 6,8 We therefore studied only those THRs in which Charnley (DePuy, Leeds, UK), Exeter (Howmedica International, Herouville, France), Titan (Landos, Chaumont, France) or Spectron/ITH (Spectron acetabulum, ITH femur; Richards, Memphis, Tennessee) components were cemented with high-viscosity Palacos (Schering-Plough International Inc, Kenilworth, New Jersey) or Simplex (Howmedica International, London, UK) cement. Among the 11998 THRs performed with systemic antibiotic prophylaxis we included only those in which the most commonly used types of systemic antibiotic, namely cephalothin $(n=6168)$, cefuroxime $(n=1969)$, dicloxacillin $(n=1468)$ and cloxacillin $(n=785)$ had been used.

In the procedures performed with antibiotic-containing cement, gentamicin was used in combination with Palacos $(0.5 \mathrm{~g}$ per $40.0 \mathrm{~g}$ polymethylmethacrylate; $\mathrm{n}=5898)$ and erythromicin/colistin with Simplex cement ( $0.5 \mathrm{~g}$ erythromicin and $0.24 \mathrm{~g}$ colistin per $40.0 \mathrm{~g}$ polymethylmethacrylate; $\mathrm{n}=145$ ).

For revisions the surgeon could record one or more reasons for failure. When seen in combination with other causes, infection was considered as the primary cause of revision. Aseptic loosening was otherwise acknowledged as the principal cause of revision.

Statistical analysis. In this survey the endpoints for survival were defined as revision for deep infection and aseptic loosening, respectively. Further analyses also used revision for any cause as the endpoint. The Central Bureau of Statistics, Oslo, Norway, provided information on deaths until February 1, 1996. The survival times of THRs in patients who had died without revision were censored. The probability of survival at five years was estimated for the different antibiotic regimes using the product-limit method. ${ }^{16}$ Multivariate Cox regression analysis ${ }^{17}$ provided effect estimates for the regimes with adjustment for the possible influence of gender, age $(<65,65$ to $74,>74$ years), cement brand (Palacos, Simplex), prosthesis type (Charnley, Exeter, Titan, Spectron/ITH), operating theatre (an enclosed area with laminar air ventilation and use of body-exhaust systems ('greenhouse')), laminar air ventilation, ordinary ventilation and the duration of the operation $(<61 \mathrm{~min}, 61$ to 120 $\min ,>120 \mathrm{~min}$ ). Cox analyses were also performed with additional adjustment for the total amount of systemic antibiotic prophylaxis given $(\leq 1.5 \mathrm{~g}, 1.6$ to $2.0 \mathrm{~g}, 2.1$ to $4.0 \mathrm{~g}, 4.1$ to $6.0 \mathrm{~g},>6.0 \mathrm{~g}$ ). Tests of the proportional hazards assumption were made for all risk factors included in the Cox regression models. ${ }^{18}$ To investigate further whether the effect of the use of antibiotics varied with time since the primary operation, Cox analyses were performed with time-dependent risk factors included. In the Cox models, we used score tests to calculate $\mathrm{p}$ values, and risk factors with more than two levels were represented with indicator variables to avoid assumptions of linear relationships. Estimates from Cox analyses were

Table I. Characteristics (percentage) of four antibiotic prophylaxis regimes used in cemented primary total hip replacements in Norway from 1987 to 1995

\begin{tabular}{|c|c|c|c|c|c|c|c|c|c|c|c|c|c|}
\hline \multirow{2}{*}{$\begin{array}{l}\text { Antibiotic } \\
\text { prophylaxis } \\
\text { regime }\end{array}$} & \multirow[b]{2}{*}{ Number } & \multirow[b]{2}{*}{ Males } & \multicolumn{2}{|c|}{ Age (yr) } & \multicolumn{4}{|c|}{ Prosthesis brand* } & \multicolumn{2}{|c|}{ Cement brand } & \multicolumn{2}{|c|}{$\begin{array}{l}\text { Operating } \\
\text { theatre } \dagger\end{array}$} & \multirow{2}{*}{$\begin{array}{l}\text { Median op } \\
\text { time (min) } \\
(95 \% \mathrm{CI})\end{array}$} \\
\hline & & & $<65$ & 65 to 74 & $\mathbf{C}$ & $\mathbf{E}$ & $\mathbf{T}$ & $\mathbf{S}$ & Palacos & Simplex & $\mathbf{G}$ & $\mathbf{L}$ & \\
\hline Combined & 5804 & 31 & 15 & 49 & 67 & 3.6 & 21 & 8.4 & 98 & 2.5 & 2.7 & 32 & $\begin{array}{l}95 \\
\text { (93.7 to } 95.3)\end{array}$ \\
\hline Systemic only & 4586 & 30 & 17 & 52 & 38 & 44 & 9.2 & 9.1 & 40 & 60 & 2.1 & 47 & $\begin{array}{l}90 \\
(89.4 \text { to } 90.6)\end{array}$ \\
\hline Cement only & 239 & 24 & 14 & 50 & 74 & 0.8 & 24 & 1.3 & 100 & 0.0 & 6.4 & 40 & $\begin{array}{l}90 \\
(85.9 \text { to } 94.1)\end{array}$ \\
\hline No antibiotic & 276 & 30 & 17 & 53 & 45 & 4.0 & 0.7 & 51 & 43 & 57 & 38 & 5.8 & $\begin{array}{l}110 \\
(107.6 \text { to } 112.4)\end{array}$ \\
\hline Total & 10905 & 31 & 16 & 50 & 55 & 20 & 16 & 9.6 & 72 & 28 & 3.4 & 38 & $\begin{array}{l}90 \\
(89.5 \text { to } 90.5)\end{array}$ \\
\hline
\end{tabular}

* $\mathrm{C}=$ Charnley; $\mathrm{E}=$ Exeter; $\mathrm{T}=$ Titan; $\mathrm{S}=$ Spectron/ITH

$\dagger \mathrm{G}=$ greenhouse; $\mathrm{L}=$ laminar air flow 
Table II. Characteristics (percentage) of systemic antibiotic prophylaxis regimes used in cemented primary total hip replacements in Norway from 1987 to 1995

\begin{tabular}{|c|c|c|c|c|c|c|c|c|c|c|}
\hline \multirow{2}{*}{$\begin{array}{l}\text { Antibiotic } \\
\text { prophylaxis } \\
\text { regime }\end{array}$} & \multirow[b]{2}{*}{ Number } & \multicolumn{2}{|c|}{ Systemic antibiotic } & \multicolumn{4}{|c|}{ Duration of administration (days) } & \multicolumn{3}{|c|}{$\begin{array}{l}\text { Daily amount of } \\
\text { systemic antibiotic }(\mathrm{g}) \div\end{array}$} \\
\hline & & Penicillins* & Cephalosporins $\dagger$ & 1 & 2 & 3 & $>\mathbf{3}$ & $\leqslant \mathbf{2 . 0}$ & 2.0 to 4.0 & $>4.0$ \\
\hline Combined & 5804 & 33 & 67 & 70 & 19 & 9.6 & 1.6 & 13 & 41 & 47 \\
\hline Systemic only & 4586 & 7.7 & 92 & 90 & 5.7 & 2.5 & 1.5 & 36 & 46 & 18 \\
\hline Total & 10390 & 22 & 78 & 79 & 13 & 6.5 & 1.6 & 23 & 43 & 34 \\
\hline
\end{tabular}

* cloxacillin $(\mathrm{n}=785)$ and dicloxacillin $(\mathrm{n}=1468)$

$\dagger$ cephalothin $(n=6168)$ and cefuroxime $(n=1969)$

$\ddagger$ calculated as total amount/days of duration

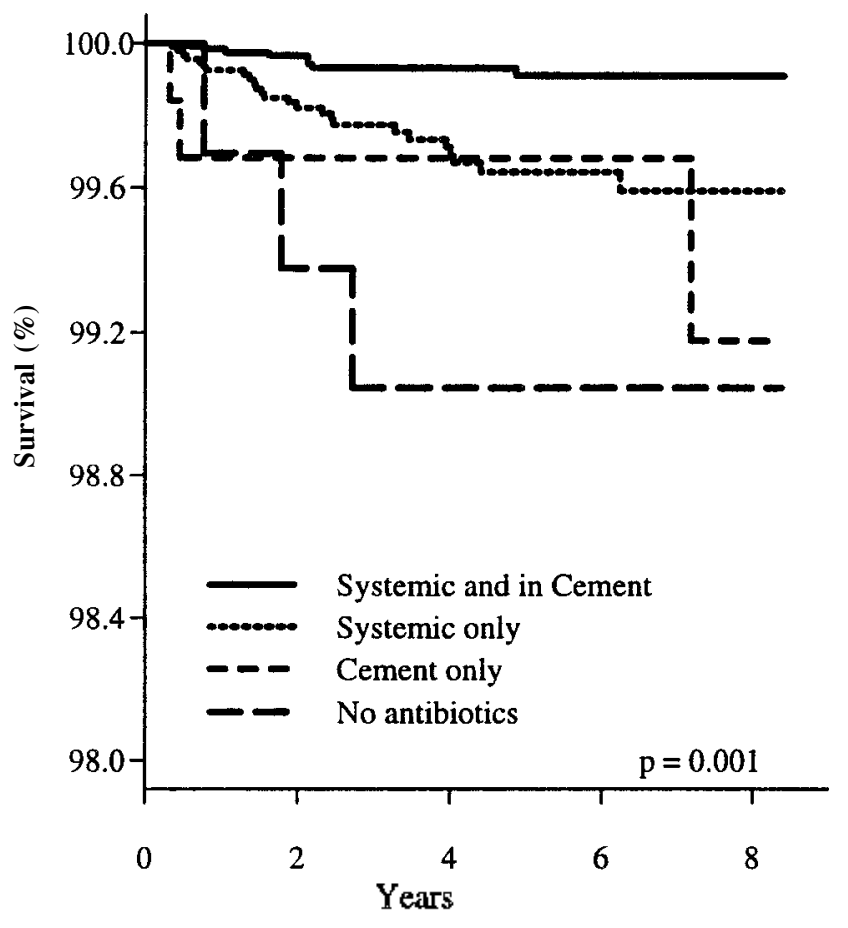

Fig. 1

Cox regression-adjusted survival curves of THRs performed in Norway from 1987 to 1995 . The probabilities of survival were calculated with revisions due to infection as the endpoint for patients receiving different antibiotic regimes for prophylaxis. The $\mathrm{p}$ value refers to a test of homogeneity showing a statistically significant difference in survival among the regimes.

used to construct adjusted survival curves at mean values of the risk factors.

The packages S-PLUS, ${ }^{19}$ SPSS $^{20}$ and BMDP $^{21}$ were used for statistical analyses.

\section{RESULTS}

Systemic antibiotics were used in $95 \%$ of the operations, $44 \%$ of which were performed with systemic antibiotics alone and $56 \%$ with a combination of antibiotics given systemically and in the bone cement (Table I). Procedures with antibiotics only in the cement accounted for $2.2 \%$ of the operations and no antibiotics were used in $2.5 \%$. The Charnley prosthesis and Palacos cement were more common among patients receiving antibiotic-containing cement

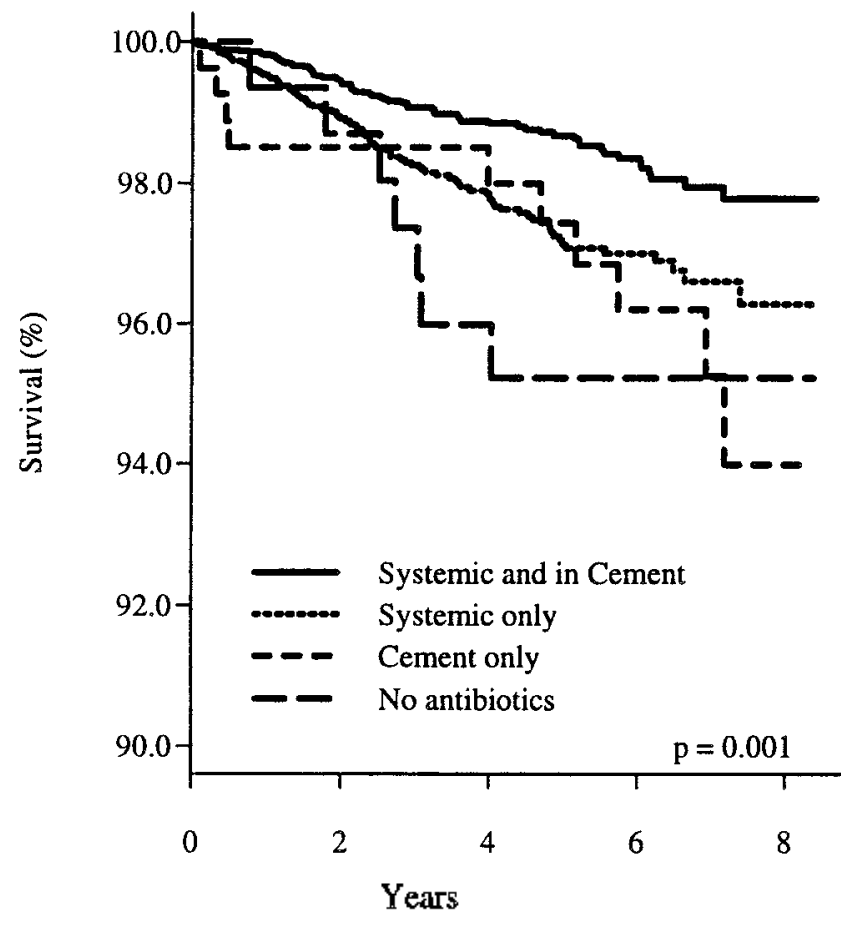

Fig. 2

Cox regression-adjusted survival curves of THRs performed in Norway from 1987 to 1995 . The probabilities of survival were calculated with revisions due to any cause as the endpoint for patients receiving different antibiotic regimes for prophylaxis. The $\mathrm{p}$ value refers to a test of homogeneity showing a statistically significant difference in survival among the regimes.

than in those having antibiotics systemically only or not receiving any antibiotics (Table I). Of procedures in which no antibiotics had been given $38 \%$ were performed in a 'greenhouse' compared with $2.5 \%$ with the other antibiotic regimes (Table I). Cephalosporins were used in $78 \%$ of operations performed with systemic antibiotics and $79 \%$ received such treatment for one day only (Table II).

Cox-adjusted survival curves for the combined, the systemic only, the cement only and the no antibiotic regimes are given in Figures 1 and 2 with revisions due to infection and revisions due to any cause as the endpoints, respectively. The figures and Table III show that the lowest probability of revision was found among patients receiving systemic antibiotic prophylaxis in combination with antibiotic-containing bone cement. With revisions 
Table III. Kaplan-Meier estimated five-year failure probabilities and Cox regression failure-rate ratios (FRR) estimated with infection, aseptic loosening and any revision as endpoints for cemented primary total hip replacements in Norway 1987 to 1995

\begin{tabular}{|c|c|c|c|c|c|c|c|c|c|}
\hline \multirow{3}{*}{$\begin{array}{l}\text { Antibiotic } \\
\text { prophylaxis } \\
\text { regime }\end{array}$} & \multirow[b]{3}{*}{ Number } & \multirow{3}{*}{$\begin{array}{l}\text { Number } \\
\text { revised }\end{array}$} & \multicolumn{2}{|c|}{ Kaplan-Meier } & \multicolumn{4}{|c|}{ Cox estimated FRR } & \multirow[b]{3}{*}{ p value } \\
\hline & & & \multirow{2}{*}{$\begin{array}{l}\text { 5-yr failure } \\
\text { prob } \\
\%\end{array}$} & \multirow{2}{*}{$95 \% \mathrm{CI}$} & \multicolumn{2}{|c|}{ Unadjusted } & \multicolumn{2}{|c|}{ Adjusted* } & \\
\hline & & & & & FRR & p value & FRR & $95 \% \mathrm{CI}$ & \\
\hline \multicolumn{10}{|c|}{ Infection as endpoint } \\
\hline Combined & 5804 & 8 & 0.2 & $(0.1$ to 0.4$)$ & 1 & & 1 & & \\
\hline Systemic only & 4586 & 25 & 0.8 & $(0.5$ to 1.1$)$ & 3.8 & 0.0004 & 4.3 & (1.7 to 11$)$ & 0.001 \\
\hline Cement only & 239 & 3 & 0.9 & $(0.0$ to 2.0$)$ & 6.4 & 0.002 & 6.3 & $(1.6$ to 25$)$ & 0.003 \\
\hline No antibiotic & 276 & 3 & 1.2 & $(0.0$ to 2.5$)$ & 5.4 & 0.005 & 11.5 & (2.1 to 63$)$ & 0.002 \\
\hline \multicolumn{10}{|c|}{ Aseptic loosening as endpoint } \\
\hline Combined & 5804 & 44 & 1.0 & $(0.7$ to 1.4$)$ & 1 & & 1 & & \\
\hline Systemic only & 4586 & 54 & 1.9 & (1.3 to 2.4$)$ & 1.5 & 0.05 & 1.8 & (1.1 to 2.9$)$ & 0.01 \\
\hline Cement only & 239 & 7 & 2.1 & $(0.0$ to 4.1$)$ & 2.4 & 0.03 & 2.6 & (1.2 to 5.9$)$ & 0.02 \\
\hline No antibiotic & 276 & 4 & 1.7 & $(0.0$ to 3.4$)$ & 1.1 & 0.83 & 2.1 & $(0.6$ to 7.3$)$ & 0.25 \\
\hline \multicolumn{10}{|c|}{ Any revision as endpoint } \\
\hline Combined & 5804 & 70 & 1.6 & $(1.2$ to 2.0$)$ & 1 & & 1 & & \\
\hline Systemic only & 4586 & 94 & 3.1 & (2.4 to 3.8$)$ & 1.6 & 0.002 & 1.8 & (1.3 to 2.7$)$ & 0.002 \\
\hline Cement only & 239 & 10 & 2.9 & $(0.5$ to 5.2$)$ & 2.2 & 0.01 & 2.5 & (1.3 to 4.9$)$ & 0.01 \\
\hline No antibiotic & 276 & 7 & 2.9 & $(0.7$ to 4.9$)$ & 1.3 & 0.49 & 2.7 & (1.0 to 7.1$)$ & 0.04 \\
\hline
\end{tabular}

* the model included antibiotic regimen, gender, age, cement- and prosthesis-brand, type of operating theatre and operating time. The number of operations included in the analysis was reduced to 10611 due to missing values

performed because of infection as the endpoint (39 cases), the adjusted Cox regression analysis showed that, compared with the combined regime, the revision rate was $4.3(95 \%$ CI 1.7 to $11.0, \mathrm{p}=0.001)$ times higher with the systemic-only regime, 6.3 (95\% CI 1.6 to 25.0, $\mathrm{p}=0.003)$ times higher with the cement-only regime and $11.5(95 \%$ CI 2.1 to $63.0, \mathrm{p}=0.002)$ times higher when no antibiotics were used (Table III). We also observed an increased rate of revision for aseptic loosening (109 cases) when comparing the systemic-only failure rate (failure rate ratio $(\mathrm{FRR})=1.8,95 \%$ CI 1.1 to 2.9 , $\mathrm{p}=0.01)$ and the cement-only failure rate $(\mathrm{FRR}=2.6$, $95 \%$ CI 1.2 to $5.9, p=0.02$ ) with the combined failure rate (Table III). Similar results were found with all revisions (181 cases) as the endpoint (Table III).

With revisions due to infection as the endpoint, the effect of the combined regime compared with the systemic-only regime was greatest during the first two years after operation $(F R R=6.0, p=0.001)$ and less during the next three years $(F R R=3.6, p=0.04)$, whereas the difference was upheld throughout the first five years with any revision as the endpoint.

A higher daily amount of systemic antibiotics and a longer period of administration were found in the combined regime (Table II). Further adjustment for the total amount of antibiotics administered systemically, however, did not change the results. With revision due to infection as the endpoint and cutpoints set at $1.5 \mathrm{~g}$ and $4.0 \mathrm{~g}$, the lowest revision rate was found among patients receiving a combined prophylaxis regimen irrespective of the total amount of systemic antibiotics administered.

When analyses were performed on operations in which systemic antibiotics were given for one day only, the results were similar to those reported for all durations. The same results were also found when restricting the material to operations performed with a Charnley prosthesis and Palacos cement with or without gentamicin.

The effect of the use of antibiotics was studied separately for operations undertaken in the three different types of operating theatre. The results in each type were similar to those estimated for the total material, and regardless of the antibiotic regime the rates for revision due to infection were not lower in operations performed in the special enclosures compared with those in ordinary theatres.

\section{DISCUSSION}

The lowest probability of revision in THRs was found among patients receiving antibiotic-containing cement in combination with systemic antibiotics. Several large studies have reported lower rates of infection for THRs undertaken with systemic antibiotic prophylaxis as compared with a placebo group. ${ }^{22-24}$ Other investigations have indicated that adding antibiotics to the cement gives better results than using plain cement only. ${ }^{25-27}$ Two randomised trials have compared the effect of antibiotics in the bone cement with antibiotics given systemically, ${ }^{13,28-30}$ but the results were inconclusive, with no difference reported in the smallest study $^{30}$ and an improvement in the rate of deep infection in the hips with antibiotic-containing cement which was not statistically significant. ${ }^{13}$ In both studies, superficial infections were more common among operations performed with antibiotic-containing cement and a concurrent use of systemic administration was suggested. ${ }^{13}$

We have shown that with revisions performed due to infection as an endpoint, the benefit of systemic antibiotics administered in combination with antibiotic-containing bone cement was highest during the first and the second years after surgery. With any revision as the endpoint the effect was upheld throughout the first five years of follow- 
up. Beyond this the numbers were too small to give estimates with sufficient precision. Other studies have also reported that antibiotic prophylaxis prevents both early infections and late hip infections. ${ }^{2431}$

The strongest estimated relative difference in rates of failure among the antibiotic prophylaxis regimes was observed with revisions due to infection as the endpoint. A similar pattern of results was seen with aseptic loosening as the endpoint. It had been shown previously that there was less aseptic loosening in operations performed with antibiotic-containing bone cement than in those with plain cement. ${ }^{6}$ Cephalothin has been shown to have an inhibitory effect on matrix metalloproteinase ${ }^{32}$ and this may reduce the risk of aseptic loosening. A similar effect was not shown for gentamicin, ${ }^{32}$ however, which was the preferred antibiotic used in bone cement in our study. A more likely explanation is that antibiotic prophylaxis prevents lowgrade infection which is unrecognised and possibly misclassified as aseptic loosening.

Concern has been expressed as to whether added antibiotics may lessen the strength of the cement. ${ }^{25} \mathrm{We}$ did not, however, find higher rates of failure due to aseptic loosening among arthroplasties with antibiotic-containing cement compared with those with plain cement, which is in accordance with other clinical studies. ${ }^{13,30,33}$ Experimental studies with mechanical tests of tensile strength have reported inferior results for antibiotic-containing cements, ${ }^{25}$ but others have shown only negligible differences. ${ }^{34}$

Palacos cement with gentamicin was used in $98 \%$ of all operations performed with antibiotics in the cement. Generalisation of our results to other types of antibiotic and cement is inappropriate, ${ }^{14}$ but restricting the analyses to operations performed with Palacos cement, which comprised $72 \%$ of the total material, yielded results very similar to those reported.

We found similar patterns of results for operations performed in ordinary operating theatres compared with those designed to lower airborne contamination. Some studies have reported similar results, ${ }^{35,36}$ but others describe an effect of systemic antibiotics in ordinary operating theatres only. ${ }^{23} \mathrm{~A}$ further reduction in rates of infection has been observed when antibiotics are used in combination with ultraclean air and body-exhaust suits. $^{35,36}$ There is as yet no convincing evidence for the beneficial effect of ultraclean-air technology. ${ }^{37}$ Irrespective of the antibiotic regime used, we did not find lower revision rates due to infection for operations performed in special operating theatres. It should be noted that relatively few operations were performed in an enclosed operating area with laminar airflow and surgeons using bodyexhaust systems ('greenhouse').

While patients operated at 14 hospitals received no antibiotic prophylaxis, $92 \%$ of such operations were performed at two centres only. At these two hospitals, the combined regime was seldom used. Thus, comparisons between the combined and the no-antibiotic regimes were based on operations from separate hospitals which possibly confounded the observed differences. Longer operating times were observed for the no-antibiotic regime, but operating times at the two hospitals were equally long for all regimes. Survival analysis within these two hospitals gave the same relation between the systemic-only regimen and the no-antibiotic regimen as was seen in the overall study. Results from multivariate analysis, however, showing the poorest survival among patients not receiving antibiotics, should be interpreted with these concerns in mind. Because this is an observational study, however, suitable blinded, randomised clinical trials are still needed to substantiate our findings further.

This study was supported by grants from the Norwegian Research Council and the Norwegian Medical Association's Fund for Quality Improvement. The authors would also like to thank Professor Grethe S. Tell at the University of Bergen, Norway, for valuable comments on the manuscript.

No benefits in any form have been received or will be received from a commercial party related directly or indirectly to the subject of this article.

\section{REFERENCES}

1. Murray DW, Carr AJ, Bulstrode CJ. Which primary total hip replacement? J Bone Joint Surg [Br] 1995;77-B:520-7.

2. Ahnfelt L, Herberts P, Malchau H, Andersson GBJ. Prognosis of total hip replacement: a Swedish multicenter study of 4,664 revisions. Acta Orthop Scand 1990;61 Suppl 238:1-26.

3. Malchau H, Herberts $\mathbf{P}$, Ahnfelt L. Prognosis of total hip replacement in Sweden: follow-up of 92675 operations performed 1978-1990. Acta Orthop Scand 1993;64:497-506.

4. Havelin LI, Espehaug B, Vollset SE, Engesaeter LB. Early failures among 14,009 cemented and 1,326 uncemented prostheses for primary coxarthrosis: The Norwegian Arthroplasty Register, 1987-1992. Acta Orthop Scand 1994;65:1-6.

5. Havelin LI, Espehaug B, Vollset SE, Engesaeter LB. Early aseptic loosening of uncemented femoral components in primary total hip replacement: a review based on the Norwegian arthroplasty register. $J$ Bone Joint Surg [Br] 1995;77:11-7.

6. Havelin LI, Espehaug B, Vollset SE, Engesaeter LB. The effect of the type of cement on early revision of Charnley total hip prostheses: a review of eight thousand five hundred and seventy-nine primary arthroplasties from the Norwegian arthroplasty register. $J$ Bone Joint Surg [Am] 1995;77-A:1543-50.

7. Havelin LI, Vollset SE, Engesaeter LB. Revision for aseptic loosening of uncemented cups in 4352 primary total hip prostheses: a report from the Norwegian arthroplasty register. Acta Orthop Scand 1995;66:494-500.

8. Espehaug B, Havelin LI, Engesaeter LB, Vollset SE, Langeland N. Early revision among 12179 hip prostheses: a comparison of 10 different brands reported to the Norwegian Arthroplasty Register, 1987-1993. Acta Orthop Scand 1995;66:487-93.

9. Norden CW. Prevention of bone and joint infections. Am J Med 1985;78(Suppl 6B):229-32.

10. Kaiser AB. Antimicrobial prophylaxis in surgery. New Eng $\mathrm{J}$ Med 1986;315:1129-38.

11. Doyon F, Evrard J, Mazas F. An evaluation of therapeutic trials published à propos of antibiotic prophylaxis in orthopaedic surgery. Rev Chir Orthop 1989;75:72-6. (Engl Abstr.)

12. Oishi CS, Carion WV, Hoaglund FT. Use of parenteral prophylactic antibiotics in clean orthopaedic surgery: a review of the literature. Clin Orthop 1993;296:249-55.

13. Josefsson G, Kolmert L. Prophylaxis with systematic antibiotics versus gentamicin bone cement in total hip arthroplasty: a ten-year survey of 1688 hips. Clin Orthop 1993;292:210-4.

14. Trippel SB. Antibiotic-impregnated cement in total joint arthroplasty. J Bone Joint Surg [Am] 1986;68:1297-302.

15. Havelin LI, Espehaug B, Vollset SE, Engesaeter LB, Langeland N. The Norwegian arthroplasty register: a survey of 17444 hip replacements 1987-1990. Acta Orthop Scand 1993;64:245-51. 
16. Kaplan EL, Meier P. Nonparametric estimation from incomplete observations. J Am Stat Assoc 1958;53:457-81.

17. Cox DR. Regression models and life tables. J Roy Stat Soc 1972; 34:187-220.

18. Grambsch PM, Therneau TM. Proportional hazards tests and diagnostics based on weighted residuals. Biometrika 1994;81:515-26.

19. Statistical Sciences Inc. S-PLUS User's Manual. Seattle: Statistical Sciences, Inc, 1995.

20. SPSS Inc. SPSS Advanced Statistics. Chicago: SPSS Inc, 1993.

21. Dixon WJ. BMDP statistical software manual. Berkeley, etc: University of California Press, 1992.

22. Pavel A, Smith RL, Ballard A, Larson IJ. Prophylactic antibiotics in elective orthopaedic surgery: a prospective study of 1591 cases. South Med J 1977;70 Suppl 1:50-5.

23. Hill C, Flamant R, Mazas F, Evrard J. Prophylactic cefazolin versus placebo in total hip replacement: report of a multicentre double-blind randomised trial. Lancet 1981;i:795-7.

24. Doyon F, Evrard J, Mazas F, Hill C. Long-term results of prophylactic cefazolin versus placebo in total hip replacement. Lancet 1987; 1:860.

25. Buchholz HW, Engelbrecht H. Depot effects of various antibiotics mixed with Palacos resins. Chirurg 1970;40:511-5.

26. Buchholz HW, Engelbrecht E, Röttger J, Siegel A. Erkenntnisse nach eechsel von über 400 infizierten hüftendoprothesen. Orthop Praxis 1977; 12:1117-20.

27. Thierse L. Erfahrungen mit Refobacin-Palacos im hinblick auf die tiefen spätinfektionen nach hüftendoprosthesenoperationen: eine 4-jahres studie. Z Orthop 1978;116:847-52. (Engl. Abstr.)
28. Josefsson G, Lindberg L, Wiklander B. Systemic antibiotics and gentamicin-containing bone cement in the prophylaxis of postoperative infections in total hip arthroplasty. Clin Orthop 1981;159: 194-200.

29. Josefsson G, Gudmundsson G, Kolmert L, Wijkström S. Prophylaxis with systemic antibiotics versus gentamicin bone cement in total hip arthroplasty: a five-year survey of 1688 hips. Clin Orthop 1990; 253:173-8.

30. McQueen MM, Hughes SPF, May P, Verity L. Cefuroxime in total joint arthroplasty: intravenous or in bone cement. J Arthroplasty 1990; 5:169-72.

31. Carlsson ÅS, Lidgren L, Lindberg L. Prophylactic antibiotics against early and late deep infections after total hip replacements. Acta Orthop Scand 1977;48:405-10.

32. Santavirta S, Takagi M, Konttinen YJ, Sorsa T, Suda A. Inhibitory effect of cephalothin on matrix metalloproteinase activity around loose hip prostheses. Antimicrob Agents Chemother 1996;40:244-6.

33. Garvin KL, Salvati EA, Brause BD. Role of gentamicin-impregnated cement in total joint arthroplasty. Orthop Clin North Am 1988;19: 605-10.

34. Marks KE, Nelson CL, Lautenschlager EP. Antibiotic-impregnated acrylic bone cement. J Bone Joint Surg [Am] 1976;58-A:358-64.

35. Lidwell OM, Lowbury EJL, Whyte W, et al. Infection and sepsis after operations for total hip or knee-joint replacement: influence of ultraclean air, prophylactic antibiotics and other factors. J Hyg (Lond) 1984;93:505-29.

36. Lidwell OM. Air, antibiotics and sepsis in replacement joints. $J$ Hosp Infect 1988;11 (Suppl C):18-40.

37. Hanssen AD, Osmon DR. Prevention of deep wound infection after total hip arthroplasty: the role of prophylactic antibiotics and clean air technology. Sem Arthroplasty 1994;5:114-21. 